\title{
Spatial Assessment of Jerusalem Artichoke's Potential as an Energy Crop in the Marginal Land of the Shaanxi Province, China
}

\author{
Fang Yin ${ }^{1}$, Ziyue Jin ${ }^{2}$, Jiazheng Zhu ${ }^{2}$, Lei Liu ${ }^{2, * \mathbb{C}}$ and Danyun Zhao ${ }^{1}$ \\ 1 Shaanxi Key Laboratory of Land Consolidation, School of Land Engineering, Chang'an University, \\ Xi'an 710054, China; yinf@chd.edu.cn (F.Y.); 2018027012@chd.edu.cn (D.Z.) \\ 2 School of Earth Science and Resources, Chang'an University, Xi' an 710054, China; \\ 2020127031@chd.edu.cn (Z.J.); zhujiazheng@chd.edu.cn (J.Z.) \\ * Correspondence: liul@chd.edu.cn; Tel.: +86-29-82339936
}

Citation: Yin, F.; Jin, Z.; Zhu, J.; Liu, L.; Zhao, D. Spatial Assessment of Jerusalem Artichoke's Potential as an Energy Crop in the Marginal Land of the Shaanxi Province, China. Sustainability 2021, 13, 13576. https:// doi.org/10.3390/su132413576

Academic Editors: Jingying Fu, Zhigang Sun and Fengming $X_{i}$

Received: 5 November 2021

Accepted: 6 December 2021

Published: 8 December 2021

Publisher's Note: MDPI stays neutral with regard to jurisdictional claims in published maps and institutional affiliations.

Copyright: (c) 2021 by the authors. Licensee MDPI, Basel, Switzerland. This article is an open access article distributed under the terms and conditions of the Creative Commons Attribution (CC BY) license (https:/ / creativecommons.org/licenses/by/ $4.0 /)$.

\begin{abstract}
As a foodstuff crop, Jerusalem artichoke has a promising prospect for providing sustainable feed-stock sources for bioenergy development. Due to relatively limited cultivated land resources in China, it is crucial to evaluate Jerusalem artichoke's potential production capacity in marginal land. Based on Jerusalem artichoke's growth and photosynthetic characteristics, the agricultural production systems simulator model (APSIM) and multi-factor integrated assessment method were integrated to provide an operational method for comprehensively evaluating the marginal land resources suitable for developing the plantation of Jerusalem artichoke in the Shaanxi province, China. The results showed that 0.73 million ha of marginal land was suitable for Jerusalem artichoke cultivation in the Shaanxi province, and 5.4 million ha of marginal land was fairly suitable for Jerusalem artichoke cultivation, with the yield reaching 44,289 kg/ha and 38,861 kg/ha, respectively. The suitable land resources are mainly located in Yan'an (0.18 million ha), Hanzhong (0.13 million ha), and Baoji (0.08 million ha), most of which are moderate dense grassland (accounting for 50.6\% of suitable land), dense grassland (accounting for $16.2 \%$ of suitable land), shrubland (accounting for $14.7 \%$ of suitable land), and sparse forest land (accounting for $9.18 \%$ of suitable land). The findings of this study can be used to establish targeted policies for Jerusalem artichoke development in China and other countries, particularly those along the Silk Road.
\end{abstract}

Keywords: bioenergy; bioethanol; agricultural production systems simulator model; Jerusalem artichoke; model re-parameterization; China

\section{Introduction}

The transition from fossil fuel to renewable energy use is effectively promoted worldwide, to mitigate climate change by reducing greenhouse gas emission [1,2]. The Global Renewables Outlook: Energy Transformation 2050, issued by the International Renewable Energy Agency (IRENA) in 2020, highlighted the path to a sustainable future energy system and studied how to reduce global $\mathrm{CO}_{2}$ emissions by at least $70.0 \%$ by 2050 [3]. China estimates to have $\mathrm{CO}_{2}$ emissions peak before 2030 and pledges to achieve carbon neutrality by 2060 , which is known as the most significant milestone of global climate policies in the past five years. A promising approach is advanced bioenergy development which has the potential to realize zero emissions. There will be increasing demand for energy crops that provide sustainable sources of feedstock for bioenergy production.

In recent years, many studies have explored suitable energy crops for converting biomass into bioethanol, and there is a considerable interest in increasing the yield of bioethanol fermentation. USA and Brazil devote $85.0 \%$ of the world's total bioethanol production, with food crops, such as corn, sugarcane, sugar beet, and wheat, used as primary feedstocks [4]. While this is only acceptable in countries with ample arable land, it remains a severe problem in China considering food production. China has 0.12 billion ha of marginal land suitable for energy crop production that has been abandoned due to their 
unsuitability for food crop production [5]. Consequently, it would be preferable to cultivate energy plants with high ecological adaptability on marginal lands [6,7]. Researchers working on bioenergy crops are increasingly interested in evaluating the potential energy plant yields of marginal lands across vast geographical areas [8,9].

Jerusalem artichoke can grow well with little water or fertilization. Its high ecological adaptability, rapid growth, large biomass, and high energy conversion efficiency make it an ideal non-food energy plant that could significantly increase marginal lands' economic value [10-12]. In the existing literature, a multi-factor integrated assessment and GIS were used to explain the influence of soil and climatic conditions, evaluate the quantity and spatial distribution of marginal land resources for planting Jerusalem artichoke in China, and finally calculate the potential total yield based on obtained land area and statistical data $[5,13,14]$. However, little research has been conducted to characterize Jerusalem artichoke's growth and photosynthetic features creation mechanism, and to analyze regional yield variances for large-scale production in marginal terrain. Therefore, the relevant results are not accurate enough to guide the specific implementation at provincial and district scales.

Crop models are helpful tools for studying crop yield formation mechanisms, which are based on processes responsible for crop growth, development, yield, and quality [15]. The most widely used crop models for energy crops are DSSAT/CANEGRO/APSIM (agricultural production systems simulator model) [16-22], and APSIM has been used for evaluating the growth of sugarcane, switchgrass, and Miscanthus [23]. Combining the characteristics of APSIM and geographic information system (GIS) technology, this study was conducted to provide an operational method for comprehensively evaluating the potential production capacity for developing the plantation of Jerusalem artichoke in marginal land resources.

In this context, using the Shaanxi province as a case study, this paper aims to (a) identify the most sensitive influence factors and predict the yield of Jerusalem artichoke using APSIM, (b) use multifactor integrated assessment method to spatially assess the total marginal land suitable for planting Jerusalem artichoke at a $100 \mathrm{~m}$ pixel size, and (c) provide feasible guidance for the development of Jerusalem artichoke plantations in the Shaanxi province by comparing filed data.

\section{Materials and Methods}

\subsection{APSIM Model}

Since Jerusalem artichoke grows underground and has similar attributes to potato, our study simulated its growth through the re-parameterization of the APSIM-Potato module on a daily time step in the APSIM Version 7.10. The following sections describe how the APSIM-potato model was validated using local meteorological and soil parameters.

\subsubsection{Meteorological Conditions}

The annual meteorological data for 31 sites in the Shaanxi province was derived from the National Meteorological Scientific Data Sharing Service Platform [24]. Daily meteorological data for each location included daily maximum and minimum temperature, solar irradiance, precipitation, and evaporation (Table S1). All the data files were classified and sorted, and outliers were removed and finally converted to the recognized met format.

Following the methodology used in the literature [25-30], climate data for daily rainfall, maximum and minimum temperature, evaporation, and solar radiation during the period 1998-2020 were used to replace consecutive absent values. Long-term monthly average minimum air temperature ranged from -12.5 to $22.0^{\circ} \mathrm{C}$, and the monthly average maximum air temperature was between -1.45 to $31.6^{\circ} \mathrm{C}$. The average annual rainfall varied from 368 to $945 \mathrm{~mm}$ for Yulin and Ankang, respectively. Annual solar radiation varied from 1102 to $612 \mathrm{MJ} / \mathrm{m}^{2}$ for Yan'an and Xi'an, respectively. Average annual evaporation varied from 18.3 to $43.2 \mathrm{~mm}$ for Ankang and Yulin, respectively. A summary of climate 
information by location is reported in Table S1. An overview of climate information by location is reported in Table S1.

\subsubsection{Soil Parameterization}

Soil types and climates can significantly vary in Shaanxi, and the local rainfall pattern is in a zonal distribution (Figure 1). Fourteen soil orders covering the site locations were used for the simulations. A complete description of the area occupied by various soil types in the districts of the Shaanxi province is provided in the supplementary information of each location (Table S2). As the soil database of the 7.10 version does not include all the above soils, new APSIM soil profiles were created. The soil of Shaanxi is divided into three layers $(15.0 \mathrm{~cm}, 30.0 \mathrm{~cm}$, and $100 \mathrm{~cm})$ in general. The dominant soil series and actual soil data (texture, organic carbon [OC], Buck density [BD], and $\mathrm{pH}$ ) of each soil series were obtained from the Harmonized World Soil Database (HWSD) [31] (see actual data in Table S3). The drained upper limit (DUL) and the lower limit (LL) were estimated based on soil texture (the content of clay, sand, and powder) and BD data from HWSD, using the soil water express model (http:/ /apsimdev.apsim.info/swe/default.aspx (accessed on 5 December 2021)), officially provided by APSIM. The airdry parameter was estimated as $0.50 \times$ LL in the $0-0.15-\mathrm{m}$ soil layer and $0.90 \times \mathrm{LL}$ in the $0.15-0.30-\mathrm{m}$ soil layer, and is equal to LL at depths $>0.30 \mathrm{~m}[26,30]$.

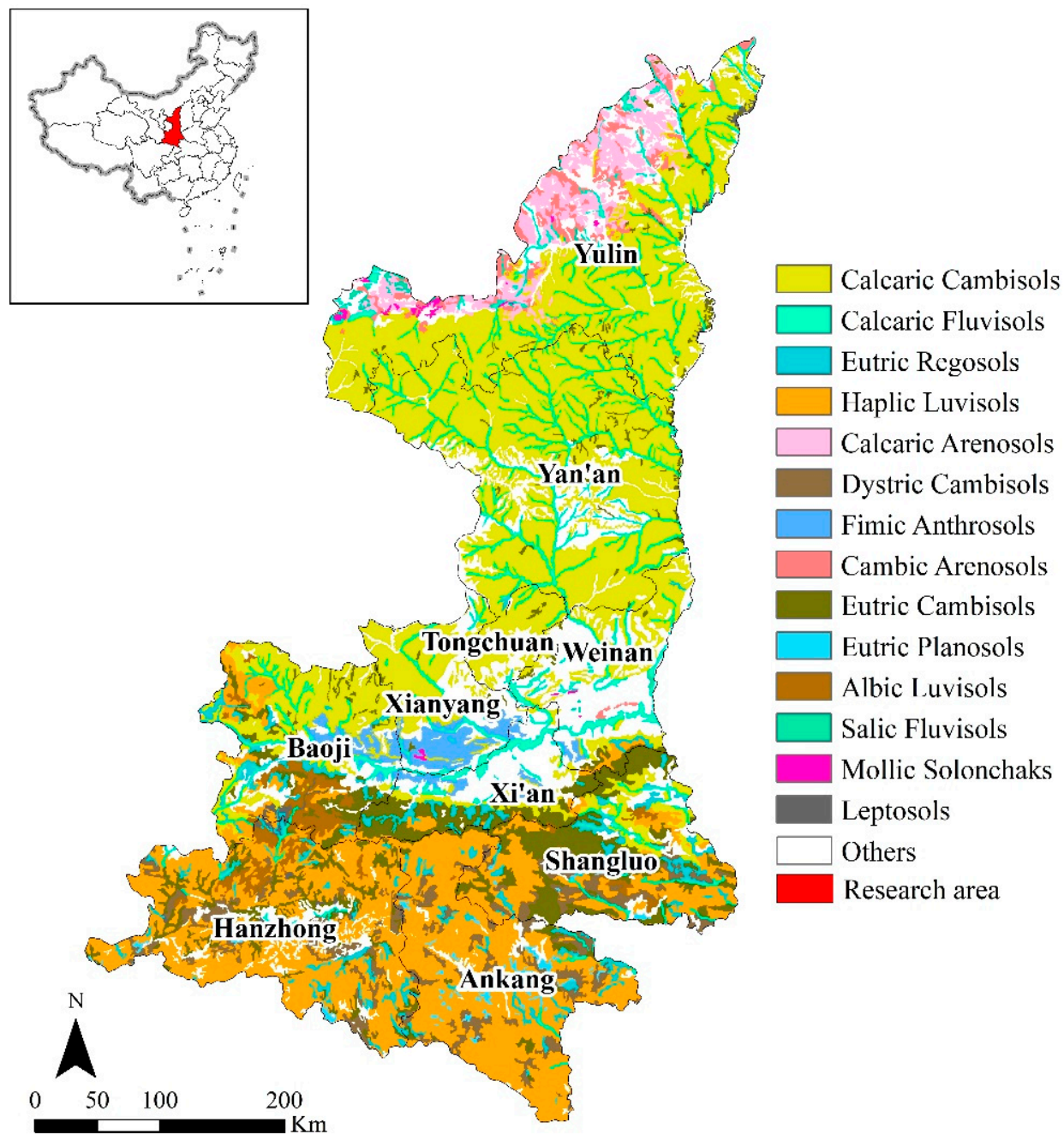

Figure 1. Spatial distribution of soil orders in the Shaanxi province. 
Furthermore, the water extraction coefficient (KL, mm/day) was set at $0.06 \mathrm{~mm}$ for each soil layer [26]. For each soil type, the $\mathrm{pH}$ value was measured in the ratio of one part of the soil to five parts of water solution. The root exploration factor (XF, 0-1.00) was set to 1 for up to $1 \mathrm{~m}$ depth and then decreased exponentially to 0.60 at the maximum soil depth [26]. The maximum rooting depth was established according to maximum soil depth when there were no impediments to crop roots. A complete description of actual and estimated soil parameters used for the calibration of APSIM is provided in the supplementary information for each location (Table S3).

Finally, in the sowing rules module, the start and end dates of the sowing were set to 15 March and 15 April, the sowing number was set to nine seeds per square meter with $40.0-60.0 \mathrm{~cm}$ spacing, and the planting depth was controlled between $9.00-12.0 \mathrm{~cm}$.

\subsection{Method: Multi-Factor Integrated Assessment}

Based on the sensitivity analysis of APSIM model parameters, the field investigation, and an exhaustive review of the literature, ten factors were selected (including evaporation, precipitation, annual maximum daily temperature, solar irradiance, annual lowest daily temperature, annual average temperature, elevation, soil depth, soil organic matter content, and terrain slope) for suitability assessment [32]. Compared with previous studies, the three factors (evaporation, solar irradiance, and annual lowest daily temperature) with the most sensitive influences on yielding in APSIM were added. All the data were transformed into raster data layers with the same spatial resolution $(100 \mathrm{~m})$ and coordinate system in ArcGIS 10.2. The research procedures are as follows:

1. In order to protect farmland and retain sustainability and biodiversity, many land cover types (e.g., farmland, forest land, wetland, and bottomland) were excluded from the original land cover data. All the nature reserves and wildlife reserves were excluded from the land use data of 2018 (supplied by China Multi-period Land Use Land Cover Remote Sensing Monitoring Data Set (CNLUCC)) (Figure 2) [33]. Considering the growth conditions of Jerusalem artichoke and the requirements of urban development, unsuitable land use types, such as waters, construction land, and bare rock land, were excluded. The seven land types (including shrubland, sparse forest land, dense grassland, moderate dense grassland, sparse dense grassland, saline land, and bare land) were investigated for the cultivation of Jerusalem artichoke [34,35].

2. The yield data from APSIM were transformed into raster data layers (obtained from 31 sites by ordinary Kriging interpolation algorithm with a spherical semivariogram model based on the soil attribute data) with the same pixel size (100 m) and coordinate system.

3. Based on the results of the single factor evaluation, a comprehensive evaluation model was developed using the literature's criteria and thresholds [7]. The multifactor integrated analysis results were overlaid on the land use and the yield data layer, from which the suitable and fairly suitable land resources for growing Jerusalem artichoke were obtained. 


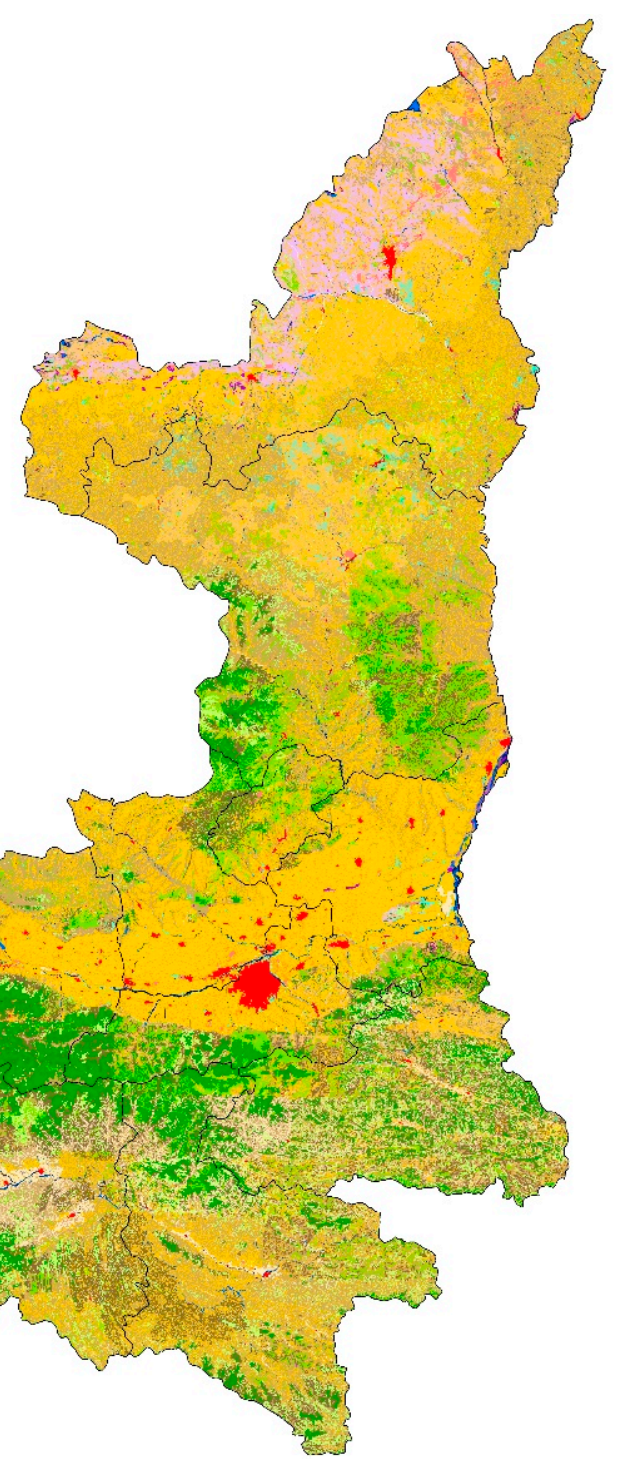

Figure 2. Land cover classification results in the Shaanxi province.

\section{Results}

\subsection{The Single-Factor Evaluation Results}

1. Slope and elevation are the most critical factors affecting the plantation of Jerusalem artichoke, because Jerusalem artichoke is most suitable for cultivation in flat terrain and altitudes up to $2500 \mathrm{~m}$ above sea level (Figure 3a,b). From the slope data, the mountainous terrain in southern Shaanxi restricted its growth, while the slope conditions in most areas of central and southern Shaanxi were suitable. From the spatial distribution of elevation, except for small parts of northwestern and central Shaanxi, the rest areas are suitable.

2. Soil factors mainly include soil organic matter content and the adequate thickness of the soil layer (Figure 3c,d). The major source of nutrients for Jerusalem artichoke growth is soil organic matter, which not only stimulates its growth and development but also improves the soil structure and increases the soil's capacity to hold water and fertilizer. Regarding the spatial distribution of organic matter content, the suitable areas are mainly located in central and southern Shaanxi. Because of the severe soil erosion, the land resources in northern Shaanxi contain a small amount of soil organic matter. 
It is observed that the soil depth will limit the cultivation of Jerusalem artichoke. Most agro-ecologies in Shaanxi are deemed suitable for this crop based on their prevailing precipitation and soil depth conditions. As its roots can grow to $0.50-2.00 \mathrm{~m}$, Jerusalem artichoke is ideal for deep plowing. The soil thicknesses are shallow in certain northern and southern regions in Shaanxi, whereas they are suitable for Jerusalem artichoke cultivation in most regions of Shaanxi.

Suitable

Fairly suitable

Unsuitable

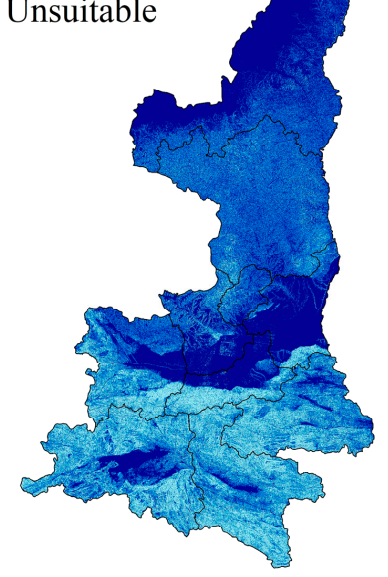

(a)

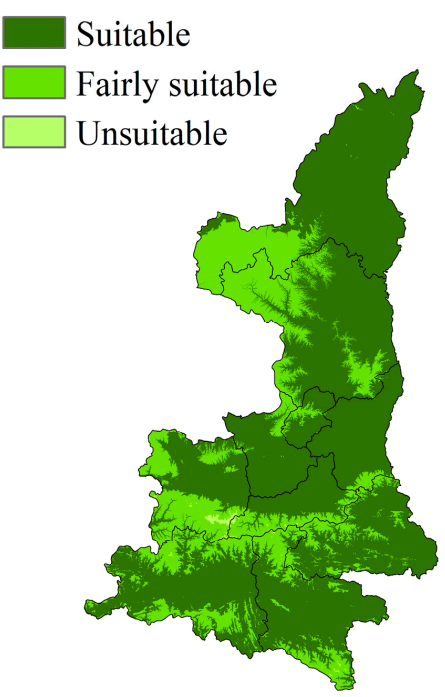

(b)
Suitable

Fairly suitable

Unsuitable

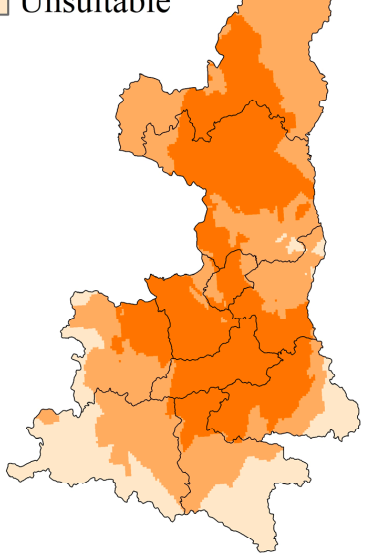

(c)
Suitable

Fairly suitable

Unsuitable

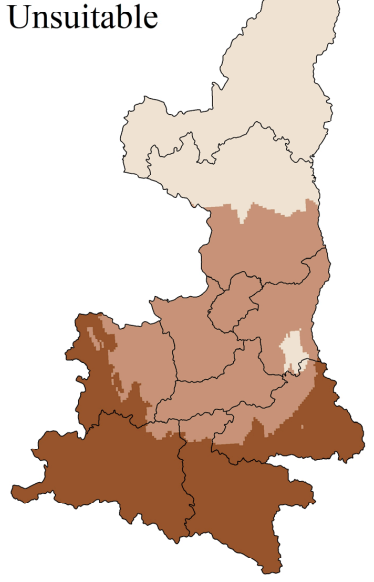

(d)

Figure 3. (a) Slope $/{ }^{\circ}$ (b) Elevation $/ \mathrm{m}$ (c) Soil depth $/ \mathrm{cm}$ (d) Organic contents $/ \%$.

3. The temperature conditions included the average annual daily minimum temperature, the average annual daily maximum temperature, and the average annual temperature (Figure $4 \mathrm{a}-\mathrm{c}$ ). The average yearly temperature was the most important factor affecting the yield of Jerusalem artichoke and was close to that of the accumulated temperature $\left(>10.0^{\circ} \mathrm{C}\right)$. 


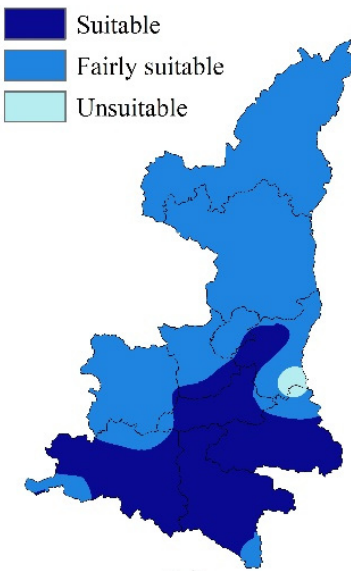

(a)

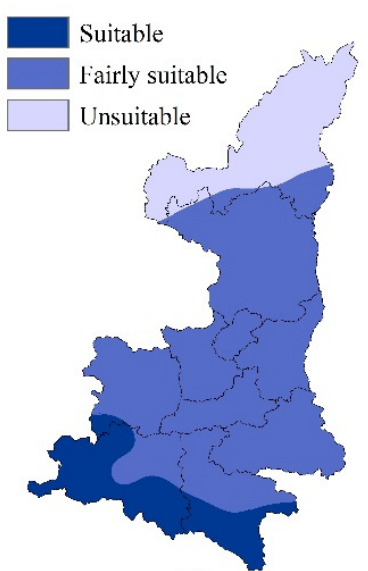

(d)

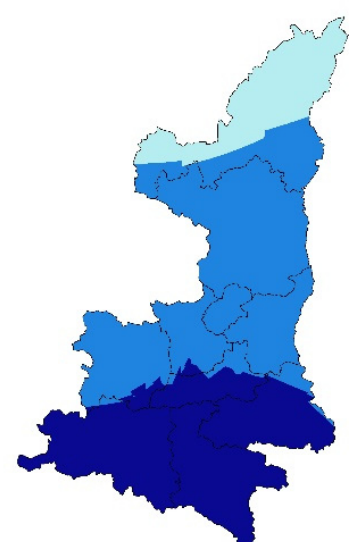

(b)

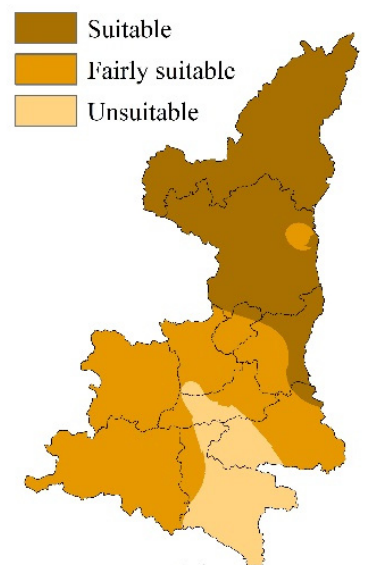

(e)

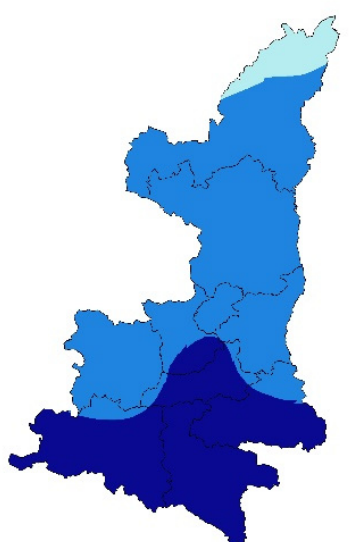

(c)

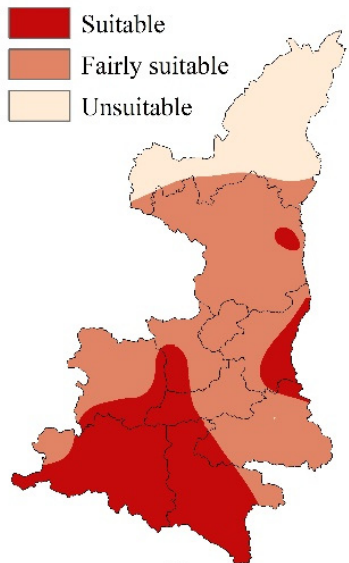

(f)

Figure 4. The single-factor evaluation results (a) The annual maximum daily temperature $/{ }^{\circ} \mathrm{C} ;(\mathbf{b})$ The lowest annual daily temperature $/{ }^{\circ} \mathrm{C}$; (c) Annual average temperature $/{ }^{\circ} \mathrm{C}$; (d) Precipitation $/ \mathrm{mm}$; (e) Solar irradiance $/ 0.1 \mathrm{MJ} / \mathrm{m}^{2}$; (f) Evaporation $/ \mathrm{mm}$.

Jerusalem artichoke has a high tolerance to temperature; it can survive either in $-40.0^{\circ} \mathrm{C}$ or even lower temperature environments or high-temperature environments, such as deserts. Too low or too high temperatures only reduce the production of Jerusalem artichoke, and they will not kill Jerusalem artichoke. Therefore, the average annual daily minimum and maximum temperatures had a relatively small impact on the development of Jerusalem artichoke. According to the temperature data, all areas are suitable for Jerusalem artichoke growth, except for a few areas in the northern Shaanxi province.

Generally, Jerusalem artichoke can use its nutrients, water, and strong roots to sprout within $30 \mathrm{~cm}$ below the sand, and its growth is unaffected by precipitation (Figure 3d). Its tuber and root system have a strong ability to store water in the rainy season, which can gradually supply the leaf stem growth in case of drought. Its above-ground stems and leaves have velvet-like tissues which can significantly reduce water evaporation. According to its drought-resistant characteristics, most agro-ecological environments in the Shaanxi province are also considered suitable. However, in the central and southern Shaanxi province, higher precipitation is considered to be more ideal, since more sufficient water can improve the yield of Jerusalem artichoke.

4. Jerusalem artichoke needs a long period of sunshine, and solar radiation can promote its photosynthesis and help it grow better, thus increasing its yield (Figure 3e). In terms of the spatial distribution of solar radiation, the northern Shaanxi is most suitable for its cultivation; the central, southwestern, and southeastern Shaanxi are more appropriate; and only a few areas in southern Shaanxi have low solar radiation with limited suitability. 
5. Jerusalem artichoke's growth is less restricted by evaporation (Figure 3f). However, if evaporation levels are too high, plants will perish, while too low evaporation will inhibit plants' transpiration. From the spatial distribution of evaporation, most areas in central and southern Shaanxi are suitable for the growth of Jerusalem artichoke.

\subsection{Multifactor Integrated Assessment Results}

The results show that the suitable cultivation areas for Jerusalem artichoke were scattered in central and southern Shaanxi, mainly including southern Yan'an; the eastern Baoji; the northern Xianyang; the central Tongchuan; Hanzhong; and a few parts of Xi'an, Weinan, and Shangluo (Figure 5). The fairly suitable area for Jerusalem artichoke planting was mainly distributed in the northern and southern Shaanxi, while most of the central areas were not suitable for Jerusalem artichoke planting and growth.

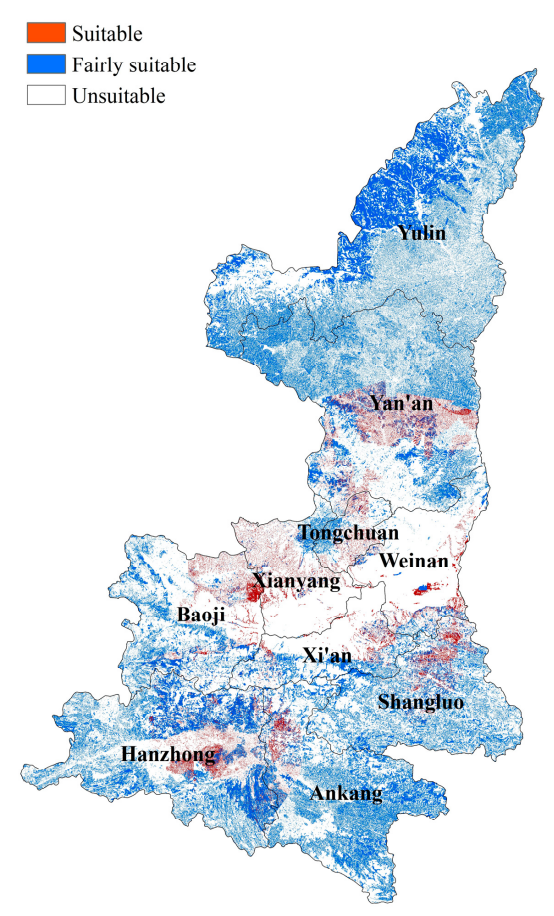

Figure 5. The suitable planting area of Jerusalem artichoke in the Shaanxi province.

The land suitability statistics for each district revealed that the regions with largest suitable land area for Jerusalem artichoke are Yan'an, Hanzhong, and Baoji with 0.18, 0.13, and 0.08 million ha, accounting for $25.3 \%, 18.7 \%$, and $12.0 \%$ of the total area, respectively (Table S4). Moreover, the regions with largest fairly suitable land area for Jerusalem artichoke are Yulin, $\mathrm{Xi}^{\prime}$ an, and Hanzhong with 1.05, 0.74, and 0.71 million ha, accounting for $19.6 \%, 13.8 \%$, and $13.3 \%$ of the total area, respectively (Table S5). In terms of the total amount, Yulin has the most abundant land resources for planting Jerusalem artichoke, and Weinan has the least. Among the land use types of marginal land that can be used for Jerusalem artichoke planting, moderate dense grassland accounts for the largest proportion, and bare land has the smallest proportion (Table S6).

From the perspective of spatial distribution characteristics, Yulin has the largest area of marginal lands available for planting Jerusalem artichoke and can select areas with higher yields for decentralized large-scale production. Xianyang, Tongchuan, and Baoji also have a relatively high proportion of suitable land areas, which can carry out concentrated planting of Jerusalem artichoke to form a complete production chain.

The yield of Jerusalem artichoke was simulated using the APSIM by considering the different conditions and process of growth. The biomasses of the last day of the growing period for the 31 sites were derived from the APSIM and interpolated using the ordinary kriging method to obtain the spatial distribution of the biomass of Jerusalem artichoke in 
the Shaanxi province (Figure 6). The estimated Jerusalem artichoke yield shows a trend of increasing first and then decreasing from the northern to southern Shaanxi. The results show higher yields in the areas of central and southwest Shaanxi (Figure 6). The results of suitable land and yield were processed using an overlay analysis method to obtain the simulated yield of suitable planting areas (Figure S1). The results showed that Yan'an had the highest simulated yield of Jerusalem artichoke, followed by Hanzhong and Baoji, while Yulin had the lowest simulated yield.

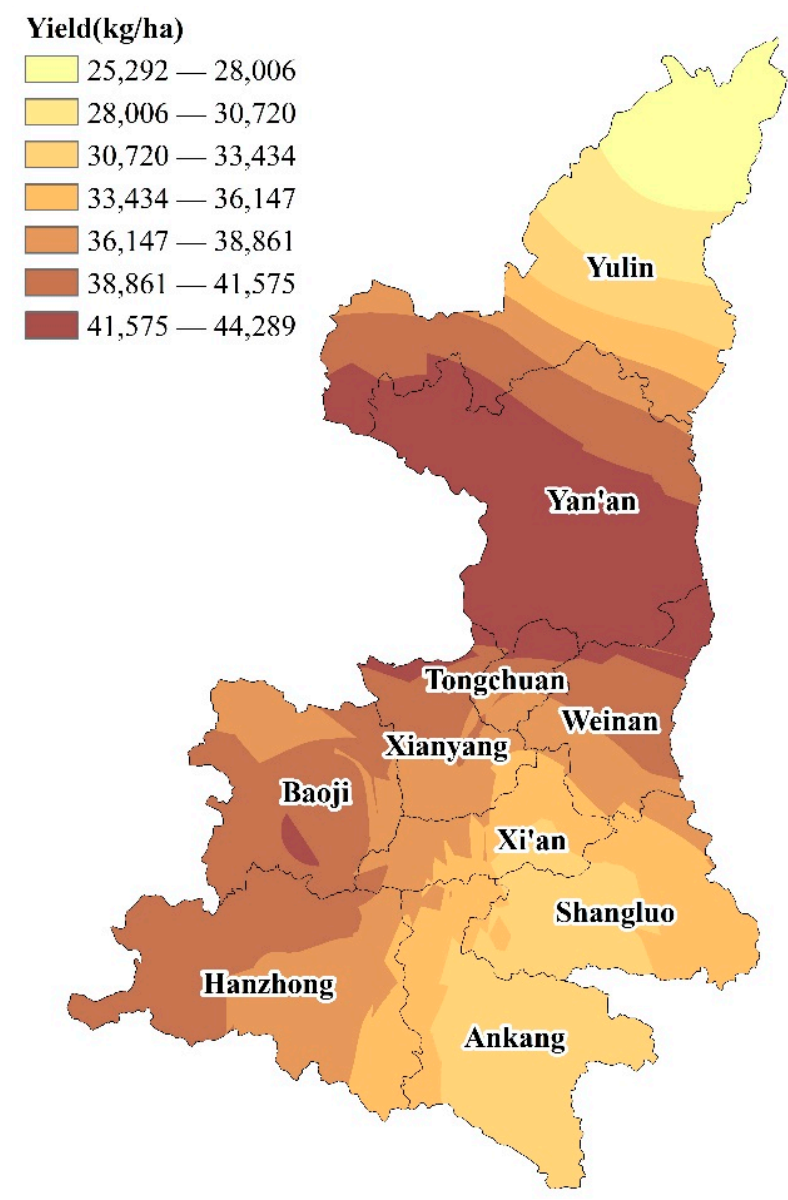

Figure 6. Simulation of yield distribution of Jerusalem artichoke in the Shaanxi province.

\subsection{Marginal Land Suitable for Planting Jerusalem Artichoke}

The statistical results show that the suitable cultivation areas for Jerusalem artichoke in Shaanxi are approximately 0.73 million ha (Figure 7). Among them, three major land cover types (moderate dense grassland, dense grassland, and shrubland) account for $81.4 \%$ of the total suitable area. Moderate dense grassland is the dominant land cover type for the growth of Jerusalem artichoke (accounting for 50.6\%). Dense grassland ranks the second (accounting for 16.2\%), and shrubland is the third (accounting for 14.7\%). The bare land has the least proportion, accounting for only $0.12 \%$ (Table S4).

Moreover, the fairly suitable areas for Jerusalem artichoke in Shaanxi are approximately 5.40 million ha. Similarly, three major land cover types (moderate dense grassland, dense grassland, sparse dense grassland) account for $73.1 \%$ of the total suitable area. Moderate dense grassland is the dominant land cover type for the growth of Jerusalem artichoke (accounting for 38.9\%), which is distributed in all the districts of Shaanxi. Dense grassland ranks the second (accounting for 19.9\%), and sparse dense grassland ranks the third (accounting for 14.3\%). The bare land has the smallest proportion, accounting for only $0.19 \%$ (Table S5). 


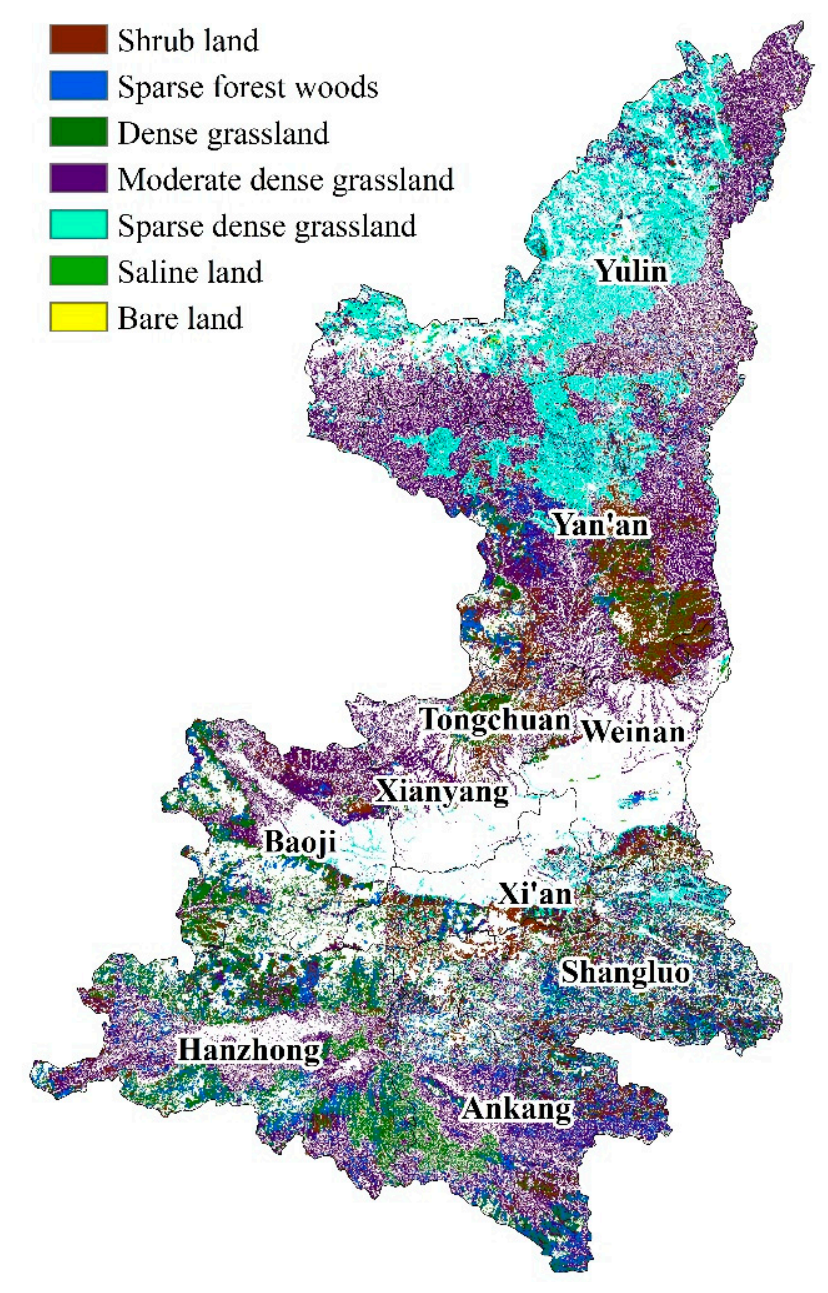

Figure 7. The distribution of land types for Jerusalem artichoke cultivation in the Shaanxi Province.

The appropriate land cover types for growing Jerusalem artichoke were dense, moderately dense, sparse grassland, and shrubland. The dense grassland was mainly distributed in middle and southern Shaanxi provinces, such as Baoji, Hanzhong, Ankang, and Tongchuan. Meanwhile, the moderately dense grassland was widely distributed in the Shaanxi province, with the maximum land areas suitable for Jerusalem artichoke growing. The sparse grassland was mainly in the north of the Shaanxi province. Besides, the shrubland in Yanan had the largest suitable land areas for Jerusalem artichoke growing. However, Yulin has the largest amount of land for cultivation of Jerusalem artichoke, most of which was at fairly suitable level. On the contrary, Xianyang, Yanan, and Baoji have relatively high ratios of suitable land to fairly suitable land.

\section{Discussion}

The simulated yield of northern Shaanxi shows a regular increase from north to south (Figure S1). It is consistent with the climate of Shaanxi that belongs to temperate zone in the north, a warm temperate zone in the middle, and a subtropical zone in the south due to the long north-south span. The natural conditions, such as precipitation, temperature, and topography, of central Shaanxi are very suitable for the cultivation of Jerusalem artichoke (Figures 3 and 4). The simulation results also show that the central area had relatively high production (Figure 6). However, the central Shaanxi has dense industrial, agricultural, and residential sites (Figure 2), which proves that the area is unsuitable for the cultivation of Jerusalem artichoke based on the criteria described in Section 2.2. Due to the mountainous topography, the soil and climate conditions are quite different in southern Shaanxi, which leads to the irregular yield distribution (Figures 3, 4 and 6). 
The spatial distribution of the suitable land for Jerusalem artichoke is in agreement with the results of previous studies [12,13]. There are large tracts of fairly suitable land in northern and southern Shaanxi (Figure 5). The northern and southern Shaanxi provinces are occupied with a large amount of suitable lands for planting Jerusalem artichoke, most of which belong to marginal land and can be used to plant Jerusalem artichoke. The centralized fertilization, irrigation, and automatic agricultural facilities in these areas will improve the land use efficiency, economic benefit, and yield. Besides, the small-scale and precision management are fit for the suitable areas in middle Shaanxi province, where the bioethanol plants could be built to produce bioethanol. Jerusalem artichoke could be optimally planted and utilized under this condition in Xianyang, Yanan, and Baoji, which have a large amount of suitable land resources.

In order to verify the result, a comparison is carried out between the result and field surveys data supplied by Shaanxi SCIPHAR Natural Products Co., Ltd. On the basis of the general investigation, the Jerusalem artichoke's planting area was maintained at about 2867 ha in Shangzhou District of Shangluo, and annually acquired 100,000 tons of underground stems. The actual yield has remained between 22,500 to $30,000 \mathrm{~kg} / \mathrm{ha}$ per year [36], which is less than the simulated yield. The continuous cultivation of Jerusalem artichoke for more than three years could lead to a decrease in production, which is the main reason for the yield difference.

In previous literature, the suitable land resources for planting Jerusalem artichoke were 11.0 million ha in the Shaanxi province [13,14]. The spatial distribution of suitable land and the most critical factor affecting the plantation of Jerusalem artichoke (slope) are basically consistent with the results of this study [13,14]. In this study, the area of suitable land resources is 6.13 million ha, which is less than that of other results [14]. The significant differences between this research and previous studies could be explained as follows. Firstly, the most sensitive factors affecting the growth of Jerusalem artichoke (such as evaporation, solar irradiance, annual lowest daily temperature) were introduced into the multi-factor integrated assessment in this research. Secondly, the influence of 100-m pixel size is very obvious for the land use and slope data (Figure 3a); therefore, the results of this research are more precise by adopting data with $100 \mathrm{~m}$ pixel size.

The APSIM model was based on meteorological and soil data, which could be affected by many uncertainties. The abnormal meteorological data were removed and unmeasured values were replaced by average values to eliminate the data error. Meanwhile, the soil water content, wilting coefficient, field water capacity, saturated water content, the upper and lower drainage limits of unconstrained soil water, and the available water capacity of plants were calculated according to the existing soil texture and soil bulk density data. However, the APSIM model cannot be used to comprehensively evaluate the land use condition and topography condition. By introducing the multi-factor-integrated assessment method, various types of factors could be combined to comprehensively evaluate the suitability of Jerusalem artichoke in the Shaanxi province. Due to the lack of data, this study only focused on the suitability for growing Jerusalem artichoke in the Shaanxi province; however, the method introduced in this research could be applied to the nationwide and even worldwide. Further, more soil and land use data were urged to improve the model certainty.

As a major province for planting Jerusalem artichoke, the government of the Shaanxi province is very supportive and ambitious towards the development of Jerusalem artichoke. The largest Jerusalem artichoke production factory in China was built in the Shangzhou district of Shangluo in 2019 with an investment worth USD 46.96 million, which could effectively promote the local economy and farmers' income in the near future. There is no doubt that the results of this study can provide a basis for estimation the supply capacity of Jerusalem artichoke, making the planting plan and policy making in the Shaanxi province. 


\section{Conclusions}

The spatial distribution, suitability of land resources, and yield for the development of Jerusalem artichoke biodiesel in the Shaanxi province are calculated, based on soil, meteorological, and land use data derived from remote sensing data, in order to accurately assess land potential and provide guidance for developing Jerusalem artichoke-based biodiesel in the future.

1. The results of this study show that the total suitable land resources for Jerusalem artichoke cultivation in the Shaanxi province are 6.13 million ha, including 0.73 million ha of suitable land and 5.40 million ha of fairly suitable land.

2. For the suitable land, moderate dense grassland is the most dominant land cover type and accounts for $50.6 \%$ of the total area. Dense grassland and shrubland are major land cover types, with proportions of $16.2 \%$ and $14.7 \%$, respectively.

3. Yulin has 1.05 million ha of land available for Jerusalem artichoke cultivation, accounting for $17.3 \%$. Xi'an, Hanzhong, Baoji, Xianyang, Tongchuan, Weinan, Shangluo, and Ankang also have some suitable land, accounting for $12.9 \%, 13.9 \%, 5.17 \%, 12.7 \%$, $11.2 \%, 4.76 \%, 5.20 \%$, and $7.22 \%$, respectively, with the least suitable land in Weinan, which has only 291,881 ha.

4. The simulation results showed that the yield of Jerusalem artichoke was best in the city of Yan'an (33,434 to 44,289 kg/ha), and in the north-central region of the Shaanxi province. The yield of Tongchuan, Weinan, Xianyang, and other cities was 30,720 to $41,575 \mathrm{~kg} / \mathrm{ha}$. In the southern part of the Shaanxi province, Ankang and Shangluo districts produced between 33,434 to $38,861 \mathrm{~kg} / \mathrm{ha}$. In general, the yield in northern Shaanxi is higher than that in southern Shaanxi, which is consistent with the above comprehensive evaluation results of multiple factors.

Supplementary Materials: The following are available online at https:/ / www.mdpi.com/article/ 10.3390/su132413576/s1, Figure S1: Yield simulation results in suitable planting areas, Table S1: Climate characterization of locations used for the calibration/validation of the Agricultural Production Systems Simulator (APSIM), Table S2: Statistical Results of Soil Types in Shaanxi Province (ha), Table S3: Attribute values of different soil types and their corresponding sites and yields, Table S4: Statistical results of land suitable for planting Jerusalem artichoke in each district in Shaanxi Province (ha), Table S5: Statistical results of land fairly suitable for planting Jerusalem artichoke in each district in Shaanxi Province (ha), Table S6: Total area of land suitable for Jerusalem artichoke planting in Each district of Shaanxi Province (ha).

Author Contributions: Conceptualization, F.Y. and Z.J.; methodology, F.Y., Z.J. and D.Z.; software, Z.J. and F.Y.; formal analysis, F.Y. and J.Z.; investigation, F.Y., Z.J. and J.Z.; resources, F.Y., J.Z. and D.Z.; data curation, F.Y., Z.J. and D.Z.; writing-original draft preparation, Z.J.; writing-review and editing, F.Y., L.L. and D.Z.; visualization, F.Y. and Z.J.; supervision, F.Y. and J.Z.; project administration, F.Y. and L.L. All authors have read and agreed to the published version of the manuscript.

Funding: This research was funded by the National Natural Science Foundation of China (42071258), Fund Project of Shaanxi Key Laboratory of Land Consolidation (2018-ZY04) and the Special Fund for Basic Scientific Research of Central Colleges (No's. 300102270204, 300102278303, 300102280401), Chang 'an University, China.

Conflicts of Interest: The authors declare no conflict of interest.

\section{References}

1. Idris, M.N.M.; Leduc, S.; Yowargana, P.; Hashim, H.; Kraxner, F. Spatio-temporal assessment of the impact of intensive palm oil-based bioenergy deployment on cross-sectoral energy decarbonization. Appl. Energy 2021, 285, 116460. [CrossRef]

2. Ingrao, C.; Bacenetti, J.; Bezama, A.; Blok, V.; Goglio, P.; Koukios, E.G.; Lindner, M.; Nemecek, T.; Siracusa, V.; Zabaniotou, A.; et al. The potential roles of bio-economy in the transition to equitable, sustainable, post fossil-carbon societies: Findings from this virtual special issue. J. Clean. Prod. 2018, 204, 471-488. [CrossRef]

3. IRENA. Global Renewables Outlook: Energy Transformation 2050. 2020. Available online: https://irena.org/publications/2020 /Apr/Global-Renewables-Outlook-2020 (accessed on 5 December 2021). 
4. Paixao, S.M.; Alves, L.; Pacheco, R.; Silva, C.M. Evaluation of Jerusalem artichoke as a sustainable energy crop to bioethanol: Energy and $\mathrm{CO}_{2}$ eq emissions modeling for an industrial scenario. Energy 2018, 150, 468-481. [CrossRef]

5. Zhuang, D.F.; Jiang, D.; Liu, L.; Huang, Y.H. Assessment of bioenergy potential on marginal land in China. Renew. Sustain. Energy Rev. 2011, 15, 1050-1056. [CrossRef]

6. Chen, Y.; Chen, F. Assessment of bioenergy potential on marginal land-A case study in Yuzhong county of Gansu. Renew Energy Resour. 2016, 34, 1079-1085.

7. Yin, F.; Yang, X.F.; Wang, H.L.; Liu, L.; Meng, X.P. Evaluation of the potential land for biofuel plant development in the Shaanxi Province, China. Geol. J. 2018, 53, 332-341. [CrossRef]

8. Clifton-Brown, J.C.; Stampfl, P.F.; Jones, M.B. Miscanthus biomass production for energy in Europe and its potential contribution to decreasing fossil fuel carbon emissions. Glob. Chang. Biol. 2004, 10, 509-518. [CrossRef]

9. Pulighe, G.; Bonati, G.; Colangeli, M.; Morese, M.M.; Traverso, L.; Lupia, F.; Khawaja, C.; Janssen, R.; Fava, F. Ongoing and emerging issues for sustainable bioenergy production on marginal lands in the Mediterranean regions. Renew. Sustain. Energy Rev. 2019, 103, 58-70. [CrossRef]

10. Dias, N.S.; Ferreira, J.F.S.; Liu, X.; Suarez, D.L. Jerusalem artichoke (Helianthus tuberosus, L.) maintains high inulin, tuber yield, and antioxidant capacity under moderately-saline irrigation waters. Ind. Crops Prod. 2016, 94, 1009-1024. [CrossRef]

11. Li, W.C.; Zhang, J.; Yu, C.W.; Li, Q.; Dong, F.; Wang, G.; Gu, G.D.; Guo, Z.Y. Extraction, degree of polymerization determination and prebiotic effect evaluation of inulin from Jerusalem artichoke. Carbohydr. Polym. 2015, 121, 315-319. [CrossRef]

12. Xu, X.L.; Li, S.; Fu, Y.; Zhuang, D.F. An analysis of the geographic distribution of energy crops and their potential for bioenergy production. Biomass Bioenergy 2013, 59, 325-335. [CrossRef]

13. Hu, N.; Yuan, B.; Sun, J.; Wang, S.A.; Li, F.L. Thermotolerant Kluyveromyces marxianus and Saccharomyces cerevisiae strains representing potentials for bioethanol production from Jerusalem artichoke by consolidated bioprocessing. Appl. Microbiol. Biotechnol. 2012, 95, 1359-1368. [CrossRef] [PubMed]

14. Liu, L. The Potential and Impacts of Biofuel Development for the Five Provinces in Southwest China. Ph.D. Thesis, Graduate School of Chinese Academy of Sciences, Beijing, China, 2011. (In Chinese).

15. Kou, Y.; Lu, S.; Liu, J.; Zhao, C. The review of Helianthus tuberosus L. and its comprehensive utilization as a bioenergy plant rich in oligosaccharide. Chin. Bull. Life Sci. 2014, 26, 451-457.

16. Lv, S.Q.; Wang, R.X.; Xiao, Y.M.; Li, F.C.; Mu, Y.W.; Lu, Y.; Gao, W.T.; Yang, B.; Kou, Y.X.; Zeng, J.; et al. Growth, yield formation, and inulin performance of a non-food energy crop, Jerusalem artichoke (Helianthus tuberosus L.), in a semi-arid area of China. Ind. Crops Prod. 2019, 134, 71-79. [CrossRef]

17. Keating, B.A.; Robertson, M.J.; Muchow, R.C.; Huth, N.I. Modelling sugarcane production systems I. Development and performance of the sugarcane module. Field Crops Res. 1999, 61, 253-271. [CrossRef]

18. Singels, A. Crop models. In Sugarcane: Physiology, Biochemistry, and Functional Biology; More, P.H., Botha, F.C., Eds.; WileyBlackwell: Hoboken, NJ, USA, 2014; pp. 541-577.

19. Jones, J.W.; Hoogenboom, G.; Porter, C.H.; Boote, K.J.; Batchelor, W.D.; Hunt, L.A.; Wilkens, P.W.; Singh, U.; Gijsman, A.J.; Ritchie, J.T. The DSSAT cropping system model. Eur. J. Agron. 2003, 18, 235-265. [CrossRef]

20. Jones, M.R.; Singels, A. Refining the Canegro model for improved simulation of climate change impacts on sugarcane. Eur. J. Agron. 2018, 100, 76-86. [CrossRef]

21. Keating, B.A.; Carberry, P.S.; Hammer, G.L.; Probert, M.E.; Robertson, M.J.; Holzworth, D.; Huth, N.I.; Hargreaves, J.N.G.; Meinke, H.; Hochman, Z.; et al. An overview of APSIM, a model designed for farming systems simulation. Eur. J. Agron. 2003, 18, 267-288. [CrossRef]

22. Holzworth, D.P.; Huth, N.I.; Devoil, P.G.; Zurcher, E.J.; Herrmann, N.I.; McLean, G.; Chenu, K.; van Oosterom, E.J.; Snow, V.; Murphy, C.; et al. APSIM-Evolution towards a new generation of agricultural systems simulation. Environ. Model. Softw. 2014, 62, 327-350. [CrossRef]

23. Holzworth, D.; Huth, N.I.; Fainges, J.; Brown, H.; Zurcher, E.; Cichota, R.; Verrall, S.; Herrmann, N.I.; Zheng, B.; Snow, V. APSIM Next Generation: Overcoming challenges in modernising a farming systems model. Environ. Model. Softw. 2018, $103,43-51$. [CrossRef]

24. The National Meteorological Scientific Data Sharing Service Platform. Available online: http:/ / data.cma.cn/ (accessed on 4 April 2021).

25. Rossini, F.; Provenzano, M.E.; Kuzmanović, L.; Ruggeri, R. Jerusalem Artichoke (Helianthus tuberosus L.): A Versatile and Sustainable Crop for Renewable Energy Production in Europe. Agronomy 2019, 9, 528. [CrossRef]

26. Liava, V.; Karkanis, A.; Danalatos, N.; Tsiropoulos, N. Cultivation Practices, Adaptability and Phytochemical Composition of Jerusalem Artichoke (Helianthus tuberosus L.): A Weed with Economic Value. Agronomy 2021, 11, 914. [CrossRef]

27. Ojeda, J.J.; Volenec, J.J.; Brouder, S.M.; Caviglia, O.P.; Agnusdei, M.G. Evaluation of Agricultural Production Systems Simulator as yield predictor of Panicum virgatum and Miscanthus $\times$ giganteus in several US environments. Glob. Chang. Biol. Bioenergy 2017, 9, 796-816. [CrossRef]

28. Ojeda, J.J.; Volenec, J.J.; Brouder, S.M.; Caviglia, O.P.; Agnusdei, M.G. Modelling stover and grain yields, and subsurface artificial drainage from long-term corn rotations using APSIM. Agric. Water Manag. 2018, 195, 154-171. [CrossRef]

29. Ojeda, J.J.; Rezaei, E.E.; Remenyi, T.A.; Webb, M.A.; Webber, H.A.; Kamali, B.; Harris, R.M.B.; Brown, J.N.; Kidd, D.B.; Mohammed, C.L.; et al. Effects of soil and climate data aggregation simulated potato yield and irrigation water requirement. Sci. Total Environ. 2020, 710, 135589. [CrossRef] [PubMed] 
30. Baldini, M.; Danuso, F.; Monti, A.; Amaducci, M.; Stevanato, P.; De Mastro, G. Chicory and Jerusalem artichoke productivity in different areas of Italy, in relation to water availability and time of harvest. Ital. J. Agron. 2006, 1, 291-307. [CrossRef]

31. Food and Agriculture Organization of the United Nations. Available online: https://www.fao.org/soils-portal/soil-survey/soilmaps-and-databases/harmonized-world-soil-database-v12/en/ (accessed on 5 December 2021).

32. Dias, H.B.; Sentelhas, P.C. Sugarcane yield gap analysis in Brazil-A multi-model approach for determining magnitudes and causes. Sci. Total Environ. 2018, 637, 1127-1136. [CrossRef]

33. Xu, X.; Liu, J.; Zhang, S.; Li, R.; Yan, C.; Wu, S.; China Multi-period Land Use Land Cover Remote Sensing Monitoring Data Set (CNLUCC). Data Registration and Publishing System of the Resource and Environmental Science Data Center of the Chinese Academy of Sciences [DB/OL] 2018. Available online: https:/ / www.resdc.cn/ (accessed on 5 December 2021).

34. Robertson, M.J.; Carberry, P.S.; Huth, N.I.; Turpin, J.E.; Probert, M.E.; Poulton, P.L.; Bell, M.; Wright, G.C.; Yeates, S.J.; Brinsmead, R.B. Simulation of growth and development of diverse legume species in APSIM. Crop Pasture Sci. 2002, 53, 429-446. [CrossRef]

35. Liu, J.Y.; Zhang, Z.X.; Zhuang, D.F.; Zhang, Z.X.; Deng, X.Z. Space pattern analysis of recently land use change in China. Sci. China Ser. D Earth Sci. 2002, 32, 1031-1041.

36. Shangzhou District People's Government. Available online: http://www.shangzhou.gov.cn/ (accessed on 5 December 2021). 